\title{
Remote Ischemic Conditioning: A Potential Treatment for Chronic Cerebral Hypoperfusion
}

\author{
Xiao Ma Chenhua Ji \\ Department of General Practice Medicine, Dalian Municipal Central Hospital, Dalian, China
}

\section{Keywords}

Remote ischemic conditioning · Chronic cerebral hypoperfusion · Pathology · Cognitive impairment

\begin{abstract}
Background: Chronic cerebral hypoperfusion $(\mathrm{CCH})$ is a clinical syndrome, which is characterized by significantly decreased cerebral blood flow (CBF). CCH is a common consequence of cerebrovascular and cardiovascular diseases and the elderly. $\mathrm{CCH}$ results in a series of pathological damages, increasing cell death, autophagy dysfunction, amyloid $\beta(A \beta)$ peptide accumulation, blood-brain barrier (BBB) disruption, and endothelial damage, which are found in $\mathrm{CCH}$ models. In addition, $\mathrm{CCH}$ is a prominent risk factor of cognitive impairment, such as vascular dementia, and $\mathrm{CCH}$ contributes to the occurrence and development of Alzheimer's disease. Therefore, the treatment of patients with $\mathrm{CCH}$ is of great value. It has been confirmed that remote ischemic conditioning (RIC) is a safe, promising treatment for acute and chronic cerebrovascular diseases. RIC significantly increases $\mathrm{CBF}$ in both $\mathrm{CCH}$ models and patients, inhibits neuronal apoptosis, reduces $A \beta$ deposition, protects BBB integrity and endothelial function, alleviates neuroinflammation, improves cognitive im-
\end{abstract}

pairment, and exerts neuroprotection. Summary: With the development of animal models, the pathophysiological mechanisms of $\mathrm{CCH}$ and RIC are increasingly revealed. Key Messages: We discuss the mechanisms related to hypoperfusion in the brain and explore the potential treatment of RIC for $\mathrm{CCH}$ to promote its transformation and application in humans.

(c) 2022 S. Karger AG, Basel

\section{Introduction}

Chronic cerebral hypoperfusion $(\mathrm{CCH})$ refers to a chronic process of pathological reduction in cerebral blood flow (CBF) due to a group of cerebral vascular and circulatory disorders. The etiology of $\mathrm{CCH}$ includes arteriosclerosis of large vessels (intracranial and extracranial large artery stenosis or occlusion), small vessel disease induced by hypertension or diabetes and vascular amyloidosis, hereditary vessel diseases such as cerebral autosomal dominant arteriopathy with subcortical infarcts and leukoencephalopathy, and hemodynamic abnormalities such as heart failure and hypotension $[1,2]$. The pathophysiological mechanisms of $\mathrm{CCH}$ include autophagy 
disorders, neuronal cell death/apoptosis, blood-brain barrier (BBB), accumulation of the amyloid $\beta(A \beta)$ peptide, endothelial damages, impaired glucose metabolism, glutamate excitotoxicity, neuroinflammation, oxidative stress, and so on [2-7].

$\mathrm{CCH}$ is considered as a major contributor of vascular cognitive impairment and neurodegenerative processes like Alzheimer's disease (AD) [7-10]; in addition, $\mathrm{CCH}$ may lead to anxiety, depression [11], and acute ischemic stroke if without treatment; therefore, early and effective treatment for $\mathrm{CCH}$ would be of great importance. In addition to the risk factors management, several drugs such as minocycline, cilostazol, and edaravone were used for $\mathrm{CCH}$ therapy in animal models [12], but there has been a major translational block in human [2]. Increasing studies revealed that remote ischemic conditioning (RIC) might alleviate the pathological changes and cognitive deficits induced by $\mathrm{CCH}$, being a promising treatment for $\mathrm{CCH}$ and vascular cognitive impairment [6].

RIC includes three methods: preconditioning (initiated before ischemia), per-conditioning (initiated during ischemia), and postconditioning (initiated after ischemia and during reperfusion) [13]. RIC was first conducted by Murry et al. [14] in 1986. They described that repetitive occlusion (5 $\mathrm{min}$ ) and reperfusion (5 min) of the left anterior descending artery by 4 cycles could reduce infarction area induced by following $45-\mathrm{min}$ period of occlusion of the same artery in the canine heart. The result demonstrated that repetitive, transient, and sublethal ischemia-reperfusion may trigger endogenous protection against the following ischemic injury. After that, numerous studies were conducted to invest the protection of ischemic conditioning to multiple organs [15-19]. Despite its advantages, the ischemic conditioning in situ is invasive and unpractical in human. Therefore, RIC, a noninvasive and well-tolerated therapy, was adopted. In RIC, repeated ischemic/reperfusion was performed on limbs and exerted protective effects against the subsequent ischemic injury in distant organs such as the brain, heart, kidneys, lungs, liver, skin flaps, ovaries, intestine, stomach, and pancreas $[10,20,21]$.

A randomized controlled trial which recruited 26 patients with acute ischemic stroke happened within $24 \mathrm{~h}$ and excluded patients receiving thrombolysis and severe disability (modified Rankin Scale score $>3$ ), and significant comorbidities showed that RIC was well tolerated and feasible and might improve National Institutes of Health Stroke Scale (NIHSS) score in 90 days [8]. Meng et al. [22] demonstrated that RIC is also protective for people with intracranial atherosclerosis. In their study, 68 cases diagnosed symptomatic intracranial arterial stenosis were enrolled, and the results proved that RIC can remarkably reduce the incidence of recurrent stroke at 90 and 300 days, shorten the recovery time (modified Rankin Scale score 0-1), and improve cerebral perfusion. Another clinical trial confirmed that RIC significantly decreased not only the incidence of recurrent stroke in 180 days but also the inflammatory stress [23]. RIC can also benefit people with small-vessel disease in visuospatial and executive ability [24]. Other studies showed that RIC significantly lowered the standard biomarkers levels at 6 and $24 \mathrm{~h}$ after severe traumatic brain injury [25], and RIC is well tolerated in patients with aneurysm subarachnoid hemorrhage and associated with good clinical outcomes [26].

Many studies in $\mathrm{CCH}$ models and patients showed that RIC could significantly increase $\mathrm{CBF}$, improve cognitive deficits, prevent neuronal cell death, protect endothelium function, alleviate neuroinflammation and oxidative stress, decrease infarct volume, and alleviate BBB leakage [27-32]. These results suggest that RIC might be a promising treatment for $\mathrm{CCH}$, but it needs more clinical studies to confirm that if RIC is suitable for $\mathrm{CCH}$ in humans.

\section{RIC Can Inhibit Apoptosis}

Apoptosis is a programmed cell death regulated by genes [33]. The number of TUNEL-positive cells and the expression of apoptosis-related proteins changed in $\mathrm{CCH}$ models [34]. Bax is an initiating apoptotic protein, caspase- 3 is a proapoptotic protein, whereas Bcl-2 is an antiapoptotic protein which could prevent neuronal apoptosis. The expression levels of Bax and caspase- 3 were significantly increased in $\mathrm{CCH}$ mice when compared with those in the sham group, whereas the Bcl-2 expression level was significantly reduced [35-37]. Therefore, the $\mathrm{Bcl}-2 / \mathrm{Bax}$ ratio decreased in $\mathrm{CCH}$ models [38].

RIC therapy significantly suppressed apoptosis in $\mathrm{CCH}$ and ischemia/reperfusion injury. In myocardium ische$\mathrm{mia} /$ reperfusion injury models, remote ischemic postconditioning may increase the level of $\mathrm{Bcl}-2 / \mathrm{Bax}$ and reduce the level of cleaved caspase-3 $[39,40]$. RIPC inhibited apoptosis and reduced apoptotic-cell proportion in ischemic stroke mice via the mitochondrial pathway [41-43]. Two weeks of remote ischemic postconditioning therapy prevented cell death and vacuolization in the cortex, corpus callosum, and hippocampus CA1 region and decreased average neuropathological score due to bilateral common 
carotid artery stenosis (BCAS) $[44,45]$. In ischemic stroke rats, RIC ameliorated neuronal death detected by the TUNEL technique and ameliorated neuronal apoptosis via both extrinsic and intrinsic apoptosis pathways [46]. According to animal studies, inhibiting neuronal apoptosis might be an important aspect by which RIC exerted neuroprotection. However, if this happens in humans, it needs further more studies to expose.

\section{eNOS/NO}

The eNOS/NO system play a crucial role in the angiogenesis and regulation of CBF after stroke [47-49]. The production of $\mathrm{NO}$ by vascular endothelium relied mainly derived from eNOS [50]. eNOS catalyzed the conversion of L-arginine to L-citrulline generating NO. NO was important for cerebral autoregulation, cerebral blood vessel expansion, inhibiting platelet adhesion, and promoting smooth muscle proliferation $[2,45,49]$. Nitrite was the storage pool of NO generated by eNOS and was reduced to NO in hypoxic conditions which acted as a mediator of preconditioning [51]. In eNOS/mice, angiogenesis was significantly impaired in the ischemic hind limb [33]. Torre et al. [52] demonstrated that the eNOS levels were significantly decreased in the hippocampal endothelium in $\mathrm{CCH}$ rats, and the eNOS inhibitor L-NIO markedly worsened spatial cognitive impairment, which indicated that nitric oxide derived from eNOS played a critical role during $\mathrm{CCH}$ by regulating microvascular tone and $\mathrm{CBF}$. However, another study showed that the phosphorylated endothelial nitric oxide synthase level was increased in the hippocampus of $\mathrm{CCH}$ models for 2 weeks. RIC treatment could sustain the increased level of phosphorylated endothelial nitric oxide synthase up to 4 weeks, elevate cerebral vessel number further, and improve spatial learning and memory compared to those without RIC treatment, and these effects could be reversed by intraperitoneal injection of NOS inhibitors [45]. It was reported that RIC treatment could also upregulate the plasma nitrite level which was related to the improvement of CBF [53]. Another experiment found that RIC upregulated mRNA expression of eNOS by about 10 folds in the blood vessels from the conditioning site and increased the level of $\mathrm{NO}$ [54]. Moreover, in the eNOS knockout mice, the neuroprotection of rapid ischemic preconditioning was absent [55]. These results suggested RIC exerted the neuroprotective effect partly through the eNOS/NO/nitrite system. Nitrite could be a promising biomarker in the peripheral blood because it was easily measured.

Effect of Remote Ischemic Conditioning

on Chronic Cerebral Hypoperfusion

\section{RIC May Improve CBF and Cognitive Decline}

Cerebral hypoperfusion is an important contributor to cognitive decline in both humans and animal models [56-60]. The cognitive decline was partly attributed to the decline of $\mathrm{CBF}$. In $\mathrm{CCH}$ models, $\mathrm{CBF}$ was reduced as much as $35 \% \sim 45 \%$ or even more than $60 \%$ of its pre-occlusion level $[61,62]$. Therefore, increase in CBF may be an effective way to ameliorate cognitive decline. Many studies demonstrated that RIC could improve CBF and cognitive impairment induced by cerebral hypoperfusion. $\mathrm{CBF}$ decreased after BCAS in the $\mathrm{CCH}$ model and showed slightly but insignificantly improvement over days [44]. The CBF reduction induced by hypoperfusion could be reversed by RIC application [45]. CBF was significantly improved in 2-week, 1-month, and 4-month RIC therapy as compared to BCAS-sham RIC, and the improvement effect of CBF could sustain to 1 week after the cessation of RIC therapy $[45,63]$. However, as for the effect of improving CBF, 1-month RIC therapy was as effective as 4-month RIC therapy at 6 months after BCAS [63]. RIC therapy could improve spatial learning and memory impairment tested by the Morris water maze test at 6 weeks after BCAS but not at 4 weeks [45]. RIC could also improve nonspatial working memory of BCAS mice tested by the NOR test [44]. Recent clinical research indicated that RIC could improve small vessel disease-related mild cognitive impairment after 1 year of therapy [24]. Therefore, RIC could be a promising treatment for neurodegenerative and neurovascular diseases.

White matter damage was a critical pathological change in vascular dementia, and the degree of leukoaraiosis was associated with cognitive impairment in the elderly [64-66]. White matter lesions were the common pathological changes in $\mathrm{CCH}$ models, and hypoperfusion was early found in the leukoaraiosis area [67, 68]. Anyhow, RIC might robustly alleviate white matter damages. In an animal study, the application of RIC therapy for 2 weeks after BCAS operation prevented the degeneration of the white matter [44]. The result was consistent with another study. Zhou et al. [10] demonstrated that RIC therapy for 1 or 4 months significantly reversed the white matter lesion induced by BCAS mice [63]. Studies about patients with intracranial atherosclerotic stenosis or cerebral small-vessel disease also suggested that long-term RIC therapy ameliorated white matter damage and improved cognitive impairment $[24,61]$. 


\section{RIC May Regulate Autophagy}

Autophagy is an intracellular degradation pathway, through which some unnecessary cellular components such as damaged proteins and organelles were degraded into metabolic elements and recycled for restoring cellular homeostasis and normal cellular functions [60, 69, 70]. Autophagy can be activated in response to diverse physiological and pathological process, such as starvation, oxidative stress, inflammatory, and immune responses, and autophagy dysregulation was observed in a wide range of disorders [71]. Accumulating evidences indicated that autophagy played essential roles in neuron physiopathological processes, and autophagy might be a promising therapeutic strategy for vascular disease [72] and neurodegenerative diseases [71]. Cerebral hypoperfusion was associated with abnormal autophagy and neurological dysfunctions [61], and autophagy modulation might play important roles in improving these disorders.

Zhang et al. [73] discussed the neuroprotection of autophagy inhibition on white matter lesions and spatial working memory in cerebral hypoperfusion mice. They revealed that autophagy activity in white matter changed over time, which was initiated at 3 days, suppressed at 10 days, and activated again at 30 days after BCAS operation, and the application of the autophagy inhibitor wortmannin could alleviate BCAS-induced white matter lesions and improve the spatial working memory. Another study demonstrated that $\mathrm{CCH}$ could improve the excessive autophagy activity and exacerbate the synaptic damage in the rat hippocampus, and URB, an autophagy inhibitor, could inhibit abnormal excessive autophagy and alleviate synaptic degradation to exert neuroprotective effects [74].

Autophagy was divided into three distinct classes, namely, microautophagy, chaperone-mediated autophagy, and macroautophagy. Macroautophagy was the major type. Autophagy was initiated by the formation of a double-membranous structure, the autophagosome. The autophagosome was then fused with a lysosome to generate an autolysosome, where the degradation occurred by specific acidic hydrolases [75]. Beclin1 was essential for the activation and regulation of autophagy, LC3 contributed to the elongation and maturation of autophagosomes, and p62 accumulation was indicative of impaired autophagic degradation [5]. RIC may regulate autophagy by multiple pathways, although the exact mechanisms remain unknown. RIC promoted Bcl-2 phosphorylation via the activation of the AKT pathway and promoted dissociation of the Bcl-2 and Beclin 1 complex, thereby leading to the induction of autophagy to exert neuroprotection in ischemic stroke rats [76]. In the ischemia/reperfusion rats, RIC might reverse the increase of the LC3-II/LC3-I ratio, Beclin1, and autophagosome numbers to relieve the induction of autophagy through the activation of the $\mathrm{mTOR} / \mathrm{p} 70 \mathrm{~S} 6 \mathrm{~K}$ signaling pathway to protect against cerebral I/R injury [77]. Wang et al. [78] showed that the combined application of remote ischemic perconditioning and remote ischemic postconditioning increased the immunoreactivity of LC3 and Beclin1 and decreased the immunoreactivity of $\mathrm{P} 62$, which suggested that the increase of autophagosome resulted from enhanced autophagy activation.

\section{RIC Can Reduce the Deposit of $A \beta$}

$\mathrm{A} \beta$ is a $36-43$-amino acid peptide, which is derived from an amyloid precursor protein after $\beta$ - and $\gamma$-secretase-mediated sequential cleavage. $A \beta 40$ and $A \beta 42$ are the main forms of existing $A \beta$ in the brain [38, $62]$. Increased $A \beta$ deposition is one of the characteristics of AD pathology [79]. Several studies have reported that $\mathrm{CCH}$ increased the $\mathrm{A} \beta$ levels and aggravated the pathology of $\mathrm{AD}[33,80-83]$. As the increased deposition of $\mathrm{A} \beta$ in the brain was resulted from the imbalance between the production and clearance, the overproduction and impaired clearance led to the deposition of $\mathrm{A} \beta$ in $\mathrm{CCH}$ models. In BCAS models, the $\mathrm{A} \beta$ generation and accumulation were increased as much as 4 -fold increase in brain areas including the frontal cortex, hippocampus CA1, and hippocampus DG by enhancing the $\beta$ - and $\gamma$-secretase levels and the increasing trends sustained until 6 months after BCAS operation $[38,44]$, although the expression of $A \beta$ in the temporal cortex was not elevated [84]. The disruption of $B B B$ influenced the clearance of $A \beta$ [9]. It was conducted that the $\mathrm{CCH}$ disrupted the structural integrity of the neuronal-glial-vascular units and disrupted the $\mathrm{BBB}$ microarchitecture to reduce the clearance of $\mathrm{A} \beta$ [85]. Impaired clearance through the glymphatic pathway from ischemic or infarcts also might contribute to the deposition of $A \beta[6]$.

RIC therapy might reduce the accumulation of $A \beta$ induced by $\mathrm{CCH}$ and prevent the progression of $\mathrm{AD}$ pathology. In BCAS mice, 2 weeks after remote ischemic postconditioning therapy, the $A \beta 42$ content was reduced by 2 -fold [44]. Studies showed that RIC treatment decreased leakage of $\mathrm{BBB}[27,86]$. The decreased leakage of $\mathrm{BBB}$ after RIC treatment was supposed to be a way through which RIC decreased the content of $A \beta$ in $\mathrm{CCH}$ models. 


\section{Conclusion}

$\mathrm{CCH}$ is a common condition in people, and $\mathrm{CCH}$ may lead to critical pathology changes and cognitive deficits, threatening people's health and life quality. RIC may restore $\mathrm{CBF}$ and cognitive functions and alleviate the pathological changes induced by $\mathrm{CCH}$, becoming a potential treatment for $\mathrm{CCH}$. The mechanism of neuroprotection against $\mathrm{CCH}$ provided by RIC needs to be investigated deeply in the future.

\section{Conflict of Interest Statement}

The authors have no conflicts of interest to declare.

\section{Funding Sources}

The authors did not receive any funding.

\section{Author Contributions}

Xiao Ma contributed to the literature search and the manuscript writing. Chenhua Ji contributed to the conception of study and manuscript modification.

\section{References}

1 O'Brien JT, Thomas A. Vascular dementia. Lancet. 2015;386:1698-706.

2 You JL, Feng LS, Bao LY, Xin MY, Ma D, Feng JC. Potential applications of remote limb ischemic conditioning for chronic cerebral circulation insufficiency. Front Neurol. 2019 May 3;10:467.

3 Li WX, Wei D, Liang JY, Xie XM, Song KP, Huang LA. Comprehensive evaluation of white matter damage and neuron death and whole-transcriptome analysis of rats with chronic cerebral hypoperfusion. Front Cell Neurosci. 2019 Jul 17;13:310.

4 Yu A, Mao L, Zhao F, Sun B. Olfactory ensheathing cells transplantation attenuates chronic cerebral hypoperfusion induced cognitive dysfunction and brain damages by activating Nrf2/HO-1 signaling pathway. Am J Transl Res. 2018 Oct;10(10):3111-21.

5 Chen X, Jiang XM, Zhao LJ, Sun LL, Yan ML, Tian Y, et al. MicroRNA-195 prevents dendritic degeneration and neuron death in rats following chronic brain hypoperfusion. Cell Death Dis. 2017 Jun;8(6):e2850.

6 Hess DC, Khan MB, Hoda N, Morgan JC. Remote ischemic conditioning: a treatment for vascular cognitive impairment. Brain Circ. 2015 Dec;1(2):133-9.

7 Du SQ, Wang XR, Xiao LY, Tu JF, Zhu W, He $\mathrm{T}$, et al. Molecular mechanisms of vascular dementia: what can be learned from animal models of chronic cerebral hypoperfusion? Mol Neurobiol. 2017 Jul;54(5):3670-82.

8 England TJ, Hedstrom A, O’Sullivan S, Donnelly R, Barrett DA, Sarmad S, et al. RECAST (remote ischemic conditioning after stroke trial): a pilot randomized placebo controlled phase II trial in acute ischemic stroke. Stroke. 2017 May;48(5):1412-5.

9 Duncombe J, Kitamura A, Hase Y, Ihara M, Kalaria RN, Horsburgh K. Chronic cerebral hypoperfusion: a key mechanism leading to vascular cognitive impairment and dementia. Closing the translational gap between rodent models and human vascular cognitive impairment and dementia. Clin Sci. 2017 Sep; 131(19):2451-68.
10 Zhou D, Ding JY, Ya JY, Pan LQ, Wang Y, Ji $\mathrm{XM}$, et al. Remote ischemic conditioning: a promising therapeutic intervention for multiorgan protection. Aging. 2018 Aug;10(8): 1825-55.

11 Lee SR, Choi B, Paul S, Seo JH, Back DB, Han JS, et al. Depressive-like behaviors in a rat model of chronic cerebral hypoperfusion. Transl Stroke Res. 2015 Jun;6(3):207-14.

12 Daulatzai MA. Cerebral hypoperfusion and glucose hypometabolism: key pathophysiological modulators promote neurodegeneration, cognitive impairment, and Alzheimer's disease. J Neurosci Res. 2017 Apr;95(4):943-72.

13 Heusch G, Bøtker HE, Przyklenk K, Redington A, Yellon D. Remote ischemic conditioning. J Am Coll Cardiol. 2015 Jan;65(2):17795.

14 Murry CE, Jennings RB, Reimer KA. Preconditioning with ischemia: a delay of lethal cell injury in ischemic myocardium. Circulation. 1986 Nov;74(5):1124-36.

15 Peralta C, Bartrons R, Serafin A, Blázquez C, Guzmán M, Prats N, et al. Adenosine monophosphate-activated protein kinase mediates the protective effects of ischemic preconditioning on hepatic ischemia-reperfusion injury in the rat. Hepatology. $2001 \mathrm{Dec} ; 34(6)$ : 1164-73.

16 Wu HH, Hsiao TY, Chien CT, Lai MK. Ischemic conditioning by short periods of reperfusion attenuates renal ischemia/reperfusion induced apoptosis and autophagy in the rat. J Biomed Sci. 2009 Feb;16(1):19.

17 Serviddio G, Romano AD, Gesualdo L, Tamborra R, Di Palma AM, Rollo T, et al. Postconditioning is an effective strategy to reduce renal ischaemia/reperfusion injury. Nephrol Dial Transplant. 2008 May;23(5): 1504-12.

18 Doeppner TR, Doehring M, Kaltwasser B, Majid A, Lin FY, Bähr M, et al. Ischemic postconditioning induces post-stroke neuroprotection via Hsp70-Mediated proteasome inhibition and facilitates neural progenitor cell transplantation. Mol Neurobiol. 2017 Oct; 54(8):6061-71.
19 Lim SY, Hausenloy DJ. Remote ischemic conditioning: from bench to bedside. Front Physiol. 2012 Feb;3:27.

20 Candilio L, Malik A, Hausenloy DJ. Protection of organs other than the heart by remote ischemic conditioning. J Cardiovasc Med. 2013 Mar;14(3):193-205.

21 Zhao WB, LiSJ, Ren CH, Meng R, Jin KL, Ji XM. Remote ischemic conditioning for stroke: clinical data, challenges, and futur e directions. Ann Clin Transl Neurol. 2018 Nov;6(1):186-96.

22 Meng R, Asmaro K, Meng L, Liu Y, Ma C, Xi CJ, et al. Upper limb ischemic preconditioning prevents recurrent stroke in intracranial arterial stenosis. Neurology. 2012 Oct;79(18): 1853-61.

23 Meng R, Ding YC, Asmaro K, Brogan D, Meng $\mathrm{L}$, Sui $\mathrm{M}$, et al. Ischemic conditioning is safe and effective for octo- and nonagenarians in stroke prevention and treatment. Neurotherapeutics. 2015 Jul;12(3):667-77.

24 Wang Y, Meng R, Song HQ, Liu G, Hua Y, Cui $\mathrm{DH}$, et al. Remote ischemic conditioning may improve outcomes of patients with cerebral small-vessel disease. Stroke. 2017 Nov;48(11): 3064-72.

25 Joseph B, Pandit V, Zangbar B, Kulvatunyou N, Khalil M, Tang A, et al. Secondary brain injury in trauma patients: the effects of remote ischemic conditioning. J Trauma Acute Care Surg. 2015 Apr;78(4):698-703.

26 Laiwalla AN, Ooi YC, Liou R, Gonzalez NR. Matched cohort analysis of the effects of limb remote ischemic conditioning in patients with aneurysmal subarachnoid hemorrhage. Transl Stroke Res. 2016 Feb;7(1):42-8.

27 Zhang W, Wang Y, Bi G. Limb remote ischaemic postconditioning-induced elevation of fibulin-5 confers neuroprotection to rats with cerebral ischaemia/reperfusion injury: activation of the AKT pathway. Clin Exp Pharmacol Physiol. 2017 Jun;44(6):656-63.

28 Li S, Hu XS, Zhang MX, Zhou FF, Lin N, Xia $\mathrm{QJ}$, et al. Remote ischemic post-conditioning improves neurological function by AQP4 down-regulation in astrocytes. Behav Brain Res. 2015 Aug;289:1-8. 
29 Li P, Su LK, Li XF, Di WY, Zhang XJ, Zhang $\mathrm{C}$, et al. Remote limb ischemic postconditioning protects mouse brain against cerebral ischemia/reperfusion injury via upregulating expression of Nrf2, HO-1 and NQO1 in mice. Int J Neurosci. 2016 Jun;126(6): 552-9.

30 Liu ZJ, Chen C, Li XR, Ran YY, Xu T, Zhang $\mathrm{Y}$, et al. Remote ischemic preconditioningmediated neuroprotection against stroke is associated with significant alterations in peripheral immune responses. CNS Neurosci Ther. 2016 Jan;22(1):43-52.

31 Hess DC, Blauenfeldt RA, Andersen G, Hougaard KD, Hoda MN, Ding YC, et al. Remote ischaemic conditioning: a new paradigm of self-protection in the brain. Nat Rev Neurol. 2015 Dec;11(12):698-710.

32 Yang T, Sun Y, Mao LL, Zhang MJ, Li QQ, Zhang LL, et al. Brain ischemic preconditioning protects against ischemic injury and preserves the blood-brain barrier via oxidative signaling and Nrf2 activation. Redox Biol. 2018 Jul;17:323-37.

33 Murohara T, Asahara T, Silver M, Bauters C, Masuda H, Kalka C, et al. Nitric oxide synthase modulates angiogenesis in response to tissue ischemia. J Clin Invest. 1998 Jun 101(11):2567-78

34 Li H, Zhou SX, Wu L, Liu KX, Zhang YH, Ma GX, et al. The role of p38MAPK signal pathway in the neuroprotective mechanism of limb postconditioning against rat cerebral ischemia/reperfusion injury. J Neurol Sci. 2015 Oct;357(1-2):270-5.

35 Hei Y, Chen R, Mao X, Wang J, Long Q, Liu W. Neuregulin 1 attenuates cognitive deficits and hippocampal CA1 neuronal apoptosis partly via ErbB4 receptor in a rat model of chronic cerebral hypoperfusion. Behav Brain Res. 2019 Jun;365:141-9.

36 Feng ZB, Lu YP, Wu XM, Zhao P, Li JJ, Peng $B$, et al. Ligustilide alleviates brain damage and improves cognitive function in rats of chronic cerebral hypoperfusion. J Ethnopharmacol. 2012 Nov; 144(2):313-21.

37 Zhang T, Gu JB, Wu LM, Li N, Sun YW, Yu $P$, et al. Neuroprotective and axonal outgrowth-promoting effects of tetramethylpyrazine nitrone in chronic cerebral hypoperfusion rats and primary hippocampal neurons exposed to hypoxia. Neuropharmacology. 2017 May;118:137-47.

38 Chen JT, Gao J, Sun WM, Li LN, Wang YH, Bai SZ, et al. Involvement of exogenous $\mathrm{H} 2 \mathrm{~S}$ in recovery of cardioprotection from ischemic post-conditioning via increase of autophagy in the aged hearts. Int J Cardiol. 2016 Oct 220:681-92.

39 Min F, Jia XJ, Gao Q, Niu F, Hu ZY, Han YL, et al. Remote ischemic post-conditioning protects against myocardial ischemia/reperfusion injury by inhibiting the Rho-kinase signaling pathway. Exp Ther Med. 2020 Jan; 19(1):99-106

40 Yu Y, Jia XJ, Zong QF, Zhang GJ, Ye HW, Hu $\mathrm{J}$, et al. Remote ischemic postconditioning protects the heart by upregulating ALDH2 expression levels through the PI3K/Akt signaling pathway. Mol Med Rep. 2014 Jul;10(1): $536-42$.

41 Lv J, Guan WK, You Q, Deng L, Zhu Y, Guo $\mathrm{K}$, et al. RIPC provides neuroprotection against ischemic stroke by suppressing apoptosis via the mitochondrial pathway. Sci Rep. 2020 Mar; 10(1):5361.

42 Gao X, Liu Y, Xie Y, Wang Y, Qi S. Remote ischemic postconditioning confers neuroprotective effects via inhibition of the BID-mediated mitochondrial apoptotic pathway. Mol Med Rep. 2017 Jul;16(1):515-22.

43 Cheng ZG, Ling L, Mo XY, Zhang L, Xie YQ, Guo QL, et al. Non-invasive remote limb ischemic postconditioning protects rats against focal cerebral ischemia by upregulating STAT3 and reducing apoptosis. Int $\mathrm{J} \mathrm{Mol}$ Med. 2014 Oct;34(4):957-66.

44 Khan MB, Hoda MN, Vaibhav K, Shailendra, Wang P, Waller JL, et al. Remote ischemic postconditioning: harnessing endogenous protection in a murine model of vascular cognitive impairment. Transl Stroke Res. 2015 Feb;6(1):69-77.

45 Ren CH, Li N, Li SJ, Han RR, Huang QJ, Hu $\mathrm{JN}$, et al. Limb ischemic conditioning improved cognitive deficits via eNOS-dependent augmentation of angiogenesis after chronic cerebral hypoperfusion in rats. Aging Dis. 2018 Oct; 9(5):869-79.

$46 \mathrm{Xu} \mathrm{W}$, Jin W, Zhang X, Chen J, Ren C. Remote limb preconditioning generates a neuroprotective effect by modulating the extrinsic apoptotic pathway and TRAIL-receptors expression. Cell Mol Neurobiol. 2017 Jan;37(1): 169-82.

47 Cui X, Chopp M, Zacharek A, Zhang C, Roberts $\mathrm{C}$, Chen J. Role of endothelial nitric oxide synthetase in arteriogenesis after stroke in mice. Neuroscience. 2009 Mar;159(2):74450.

48 Bir SC, Xiong Y, Kevil CG, Luo J. Emerging role of PKA/eNOS pathway in therapeutic angiogenesis for ischaemic tissue diseases. Cardiovasc Res. 2012 Jul;95(1):7-18.

49 Qin C, Yan XL, Jin H, Zhang RY, He YD, Sun $\mathrm{X}$, et al. Effects of remote ischemic conditioning on cerebral hemodynamics in ischemic stroke. Neuropsychiatr Dis Treat. 2020 Jan; 16:283-99.

50 Jeffrey Man HS, Tsui AK, Marsden PA. Nitric oxide and hypoxia signaling. Vitam Horm. 2014;96:161-92.

51 Rassaf T, Totzeck M, Hendgen-Cotta UB, Shiva S, Heusch G, Kelm M, et al. Circulating nitrite contributes to cardioprotection by remote ischemic preconditioning. Circ Res. 2014 May; 114(10):1601-10.

52 Torre JC, Aliev G. Inhibition of vascular nitric oxide after rat chronic brain hypoperfusion: spatial memory and immunocytochemical changes. J Cereb Blood Flow Metab. 2005 Jun; 25(6):663-72

53 Hess DC, Hoda MN, Khan MB. Humoral mediators of remote ischemic conditioning: im- portant role of eNOS/NO/Nitrite. Acta Neurochir Suppl. 2016;121:45-8

54 Hoda MN, Hess DC, Ergul A, Fagan SC. Response to letter regarding article, "remote ischemic perconditioning is effective alone and in combination with intravenous tissuetype". Stroke. 2013 Apr;44(4):e37.

55 Hess DC, Hoda MN, Bhatia K. Remote limb perconditioning (corrected) and postconditioning: will it translate into a promising treatment for acute stroke? Stroke. $2013 \mathrm{Apr}$; 44(4):1191-7.

56 Kudo T, Tada K, Takeda M, Nishimura T. Learning impairment and microtubule-associated protein 2 decrease in gerbils under chronic cerebral hypoperfusion. Stroke. 1990 Aug;21(8):1205-9.

57 Ohta H, Nishikawa H, Kimura H, Anayama $\mathrm{H}$, Miyamoto M. Chronic cerebral hypoperfusion by permanent internal carotid ligation produces learning impairment without brain damage in rats. Neuroscience. 1997 Aug; 79(4):1039-50.

58 Watanabe $\mathrm{T}$, Zhang $\mathrm{N}$, Liu M, Tanaka $\mathrm{R}$ Mizuno Y, Urabe T. Cilostazol protects against brain white matter damage and cognitive impairment in a rat model of chronic cerebral hypoperfusion. Stroke. 2006 Jun;37(6): 1539-45.

59 Ruitenberg A, Heijer T, Bakker SLM, Swieten JC, Koudstaal PJ, Hofman A, et al. Cerebral hypoperfusion and clinical onset of dementia: the Rotterdam study. Ann Neurol. 2005 Jun; 57(6):789-94.

60 Klionsky DJ, Abdelmohsen K, Abe A, Abedin MJ, Abeliovich H, Arozena AA, et al. Guidelines for the use and interpretation of assays for monitoring autophagy. Autophagy. 2016; 12(1):1-222.

61 Zou W, Song Y, Li Y, Du Y, Zhang X, Fu J. The role of autophagy in the correlation between neuron damage and cognitive impairment in rat chronic cerebral hypoperfusion. Mol Neurobiol. 2018 Jan;55(1):776-91.

62 Kitagawa K, Saitoh M, Ishizuka K, Shimizu S. Remote limb ischemic conditioning during cerebral ischemia reduces infarct size through enhanced collateral circulation in murine focal cerebral ischemia. J Stroke Cerebrovasc Dis. 2018 Apr;27(4):831-8.

63 Khan MB, Hafez S, Hoda MN, Baban B, Wagner J, Awad ME, et al. Chronic remote ischemic conditioning is cerebroprotective and induces vascular remodeling in a VCID model Transl Stroke Res. 2018 Feb;9(1):51-63.

64 Inzitari D, Pracucci G, Poggesi A, Carlucci G, Barkhof $\mathrm{F}$, Chabriat $\mathrm{H}$, et al. Changes in white matter as determinant of global functional decline in older independent outpatients: three year follow-up of LADIS (leukoaraiosis and disability) study cohort. BMJ. 2009 Jul;339: b2477.

65 Reimer MM, McQueen J, Searcy L, Scullion G, Zonta B, Desmazieres A, et al. Rapid disruption of axon-glial integrity in response to mild cerebral hypoperfusion. J Neurosci. 2011 Dec;31(49):18185-94. 
66 Fernando MS, Simpson JE, Matthews F, Brayne C, Lewis CE, Barber R, et al. White matter lesions in an unselected cohort of the elderly: molecular pathology suggests origin from chronic hypoperfusion injury. Stroke. 2006 Jun;37(6):1391-8.

67 Shibata M, Ohtani R, Ihara M, Tomimoto H. White matter lesions and glial activation in a novel mouse model of chronic cerebral hypoperfusion. Stroke. 2004 Nov;35(11):2598-603.

68 Bink DI, Ritz K, Aronica E, Weerd L, Daemen MJ. Mouse models to study the effect of cardiovascular risk factors on brain structure and cognition. J Cereb Blood Flow Metab. 2013 Nov;33(11):1666-84.

69 Galluzzi L, Pietrocola F, Levine B, Kroemer G. Metabolic control of autophagy. Cell. 2014 Dec;159(6):1263-76.

70 Thiebaut AM, Hedou E, Marciniak SJ, Vivien D, Roussel BD. Proteostasis during cerebral ischemia. Front Neurosci. 2019 Jun;13:637.

71 Rubinsztein DC, Codogno P, Levine B. Autophagy modulation as a potential therapeutic target for diverse diseases. Nat Rev Drug Discov. 2012 Sep;11(9):709-30.

72 Vindis C. Autophagy: an emerging therapeutic target in vascular diseases. Br J Pharmacol. 2015 May;172(9):2167-78.

73 Zhang SQ, Ding FF, Liu Q, Tian YY, Wang W, Qin C. Autophagy inhibition exerts neuroprotection on white matter ischemic damage after chronic cerebral hypoperfusion in mice. Brain Res. 2019 Oct;1721:146337.
$74 \mathrm{Su} \mathrm{SH}, \mathrm{Wu}$ YF, Wang DP, Hai J. Inhibition of excessive autophagy and mitophagy mediates neuroprotective effects of URB597 against chronic cerebral hypoperfusion. Cell Death Dis. 2018 Jun;9(7):733.

75 Jiang X, Niu XL, Guo QJ, Dong YH, Xu J, Yin $\mathrm{N}$, et al. FoxO1-mediated autophagy plays an important role in the neuroprotective effects of hydrogen in a rat model of vascular dementia. Behav Brain Res. 2019 Jan;356:98-106.

76 Qi ZF, Dong W, Shi WJ, Wang RL, Zhang CC, Zhao YM, et al. Bcl-2 phosphorylation triggers autophagy switch and reduces mitochondrial damage in limb remote ischemic conditioned rats after ischemic stroke. Transl Stroke Res. 2015 Jun;6(3):198-206.

77 Chen GZ, Shan XY, Li XS, Tao HM. Remote ischemic postconditioning protects the brain from focal ischemia/reperfusion injury by inhibiting autophagy through the mTOR/ p70S6K pathway. Neurol Res. 2018 Mar; 40(3): 182-8.

78 Wang J, Han D, Sun M, Feng J. A combination of remote ischemic perconditioning and cerebral ischemic postconditioning inhibits autophagy to attenuate plasma HMGB1 and induce neuroprotection against stroke in rat. J Mol Neurosci. 2016 Apr;58(4):424-31.

79 Kitaguchi $\mathrm{H}$, Tomimoto $\mathrm{H}$, Ihara $\mathrm{M}$, Shibata M, Uemura K, Kalaria RN, et al. Chronic cerebral hypoperfusion accelerates amyloid beta deposition in APPSwInd transgenic mice. Brain Res. 2009 Oct;1294:202-10.
80 Zlokovic BV. Neurovascular pathways to neurodegeneration in Alzheimer's disease and other disorders. Nat Rev Neurosci. 2011 Nov:12(12):723-38.

81 Koike MA, Green KN, Blurton-Jones M, Laferla FM. Oligemic hypoperfusion differentially affects tau and amyloid-(beta). Am J Pathol. 2010 Jul;177(1):300-10.

82 Back DB, Kwon KJ, Choi DH, Shin CY, Lee J, Han SH, et al. Chronic cerebral hypoperfusion induces post-stroke dementia following acute ischemic stroke in rats. J Neuroinflammation. 2017 Nov;14(1):216.

83 Cai Z, Liu Z, Xiao M, Wang C, Tian F. Chronic cerebral hypoperfusion promotes amyloidbetapathogenesisviaactivating $\beta / \gamma$-secretases. Neurochem Res. 2017 Dec;42(12):3446-55.

84 Park JH, Hong JH, Lee SW, Ji HD, Jung JA, Yoon KW, et al. The effect of chronic cerebral hypoperfusion on the pathology of Alzheimer's disease: a positron emission tomography study in rats. Sci Rep. 2019 Oct;9(1): 14102.

85 Wang L, Du Y, Wang K, Xu G, Luo S, He G. Chronic cerebral hypoperfusion induces memory deficits and facilitates $\mathrm{A} \beta$ generation in C57BL/6J mice. Exp Neurol. 2016 Sep;283: 353-64.

86 Ren $\mathrm{CH}$, Gao MQ, Dornbos D, Ding YC, Zeng XW, Luo YM, et al. Remote ischemic post-conditioning reduced brain damage in experimental ischemia/reperfusion injury. Neurol Res. 2013 Jun;33(5):514-9.
Effect of Remote Ischemic Conditioning on Chronic Cerebral Hypoperfusion
Eur Neurol 2022:85:253-259 